\title{
Evaluation of Fig Powder as Prebiotic and its Utilization for Development of Synbiotic Microcapsules
}

\author{
Urvi Thakkar and R. Preetha* \\ Department of Food Process Engineering, SRM University, \\ Kattankulathur Campus, Tamilnadu - 603203, India. \\ http://dx.doi.org/10.13005/bbra/2156
}

(Received: 28 March 2016; accepted: 20 April 2016)

\begin{abstract}
Lactobacillus spp. is known to be tolerant to bile and low $\mathrm{pH}$ and has probiotic effects due to multiple mechanisms. Prebiotics act as a substrate for the growth and/or activation of beneficial colonic bacteria. Ficus carica, commonly known as "Fig" belongs to Moraceae family. The aim of this study was to evaluate the use of fig powder as a potential prebiotic for Lactobacillus spp. and to develop synbiotic microcapsules. Fig powder was evaluated for its resistant starch content which was quantified to $18.04 \%$ with $\mathbf{2 . 0 6} \%$ of soluble fibers. Haurrsen's ratio for the prepared fig powder was found to be 1.1763 while Carr's Index was 14.99 , indicating 'good' flow properties. Solubility of $60 \%$ and swelling capacity of $\mathbf{4 0 0 - 5 0 0 \%}$ was observed. Also, the viability of probiotic culture in MRS medium and MRS medium incorporated of fig powder was found to be $3.3 \pm 0.05$ $\times 10^{9} \mathrm{cfu} / \mathrm{ml}$ and $5.8 \pm 0.05 \times 10^{9} \mathrm{cfu} / \mathrm{ml}$ respectively. Increased viability is attributed to presence of resistant starch. Probiotics were then encapsulated with and without prebiotic. Survivability of probiotics entrapped in alginate and synbiotic microcapsules was determined at room temperature. Probiotics entrapped in synbiotic microcapsules showed better viability, thus having better storage period.
\end{abstract}

Keywords: Prebiotic, probiotic, lactobacillus spp., resistant starch.

Prebiotics are known as "Non-digestible food ingredient that beneficially affects the host by selectively stimulating the growth and/or activity of one or a limited number of bacteria in the colon, and thus improves host health"1. A particular food product can be claimed as a prebiotic if; its hydrolyses or absorption does not take place in the upper part of the digestive system; it acts as a substrate for the growth and/or activation of beneficial colonic bacteria; it improves the composition of colon microflora; and it induces beneficial luminal effects to the health of the host² Various categories of prebiotics include some nondigestible carbohydrates or dietary fibers (oligosaccharides and polysaccharides), some peptides and proteins, and some lipids ${ }^{3}$. According to the European Food Safety Authority dietary

\footnotetext{
* To whom all correspondence should be addressed. Tel.: 9176610351;

E-mail: preetha.r@ktr.srmuniv.ac.in
}

fibers are classified into four groups: Non-starch polysaccharides (cellulose, hemicelluloses, pectin and hydrocolloids), resistant oligosaccharides like galacto-oligosaccharides (GOSs) and fructooligosaccharides (FOSs), lignin which usually associates with dietary fibers and resistant starch such as retrograded amylose, raw starch granules, and chemically modified starches ${ }^{4}$. Resistant starch may not be digested because of its dense molecular configuration protected by botanical cell wall inhibits the accessibility and action of digestive enzymes. Gelatinization is a process in which starch granules are disrupted when heated under high humidity. These gels after cooling form retrograded starch crystals which are resistant to enzymatic digestion and thus are categorised under resistant starches $^{5}$.

The most significant species belonging to Ficus genera found in India are F. bengalensis, F. carica, F. racemosa and F. elastica. Ficus carica, 
commonly known as "Fig” belongs to Moraceae family. The fruits and leaves parts have significant level of antioxidant and antimicrobial activity ${ }^{6,7}$. The antioxidant properties are attributed to the presence of total phenolics, flavonoids, alkaloids and saponins and other secondary metabolites. Consuming dried fig daily enhanced the antioxidant capacity of plasma ${ }^{8}$. Fig also has laxative properties. Dried fig fruit is a good source of carbohydrates and minerals while it has average protein and dietary fiber content with very low amount of fat and is hence considered as the richest nutritional source.

Encapsulation techniques can be applied to introduce viable probiotic bacteria as the wall material and can provide a physical barrier to the encapsulated material against adverse environmental conditions ${ }^{9,10}$. Commonly used encapsulation methods include emulsion, extrusion, spray drying, freeze drying, spray-freeze drying ${ }^{11}$.

The natural resistant starch from green banana flour and retrograded rice flour could protect the cell and promote survival of $L$. bulgaricus (TISTR 895) ${ }^{12}$. In this study Lactobacillus strain ordered from NCIM, Pune is used as probiotic strain while the potential use of Ficus carica powder as a source of prebiotic, due to its resistant starch content and other therapeutic benefits, is determined. Synbiotic microcapsules were developed using fig powder as prebiotic and storage studies were conducted.

\section{MATERIALSAND METHODS}

Fresh ripened fig fruits were purchased from the local market, of Chennai, India. These were used in preparation of custard. DPPH was used for antioxidant assay. Freeze dried Lactobacillus strain was procured from NCIM-CSIR; National Chemical Laboratory, Pune. MRS broth and MRS agar were used for growing the probiotic. Bile salt, $\mathrm{NaCl}$ and pepsin were used for conducting tolerance tests on probiotics.

\section{Preparation of Prebiotic Powder}

Pulp from fresh figs was prepared (without peeling) using grinder. The pulp was lyophilised (Temperature: $-40^{\circ} \mathrm{C}$, Pressure: -3mbar) for $30 \mathrm{hr}^{13}$. The freeze dried pulp was then ground and the powder so obtained was stored at room temperature $\left(30^{\circ} \mathrm{C}\right)$ in sealed aluminium pouches.

\section{Physical Parameters}

\section{Moisture Content and Water Activity}

The moisture content was determined using the air oven method (AOAC 2000). The samples were weighed initially dried in the oven at $105^{\circ} \mathrm{C}$. Readings were taken every half hour to determine loss in weight till constant weight is obtained. Final weight is recorded. The moisture content was calculated from the weight difference between the original and dried sample and expressed in percentage. Water activity of the prebiotic powder was calculated using Novasina Lab Swift Water Activity Meter

Moisture Content (wet basis) \% = [ (Initial

Weight-Final Weight)/Initial Weight] x 100

\section{Color Measurement}

Colour value of the prebiotic powder was measured using Colour Quest XE Hunter Colour Meter. The L, a, b chroma system uses the corresponding value of total colour difference (DE) as dynamic parameters, was used to analyze the dynamic change in the indicator's colour ${ }^{14}$. The total colour difference (TCD) is expressed as follows:

Where,

$$
\mathrm{DE}=\left[(\mathrm{DL})^{2}+(\mathrm{Da})^{2}+(\mathrm{Db})^{2}\right]^{1 / 2}
$$

$\mathrm{DL}=$ brightness difference between initiation and each time interval (value should be 0-100)

$\mathrm{Da}=$ redness-greenness difference between initiation and each time interval

$\mathrm{Db}=$ yellowness-blueness difference between initiation and each time interval

\section{Bulk Density}

The bulk density was measured ${ }^{15} .30 \mathrm{~g}$ weight of powder was poured in to a $100 \mathrm{ml}$ measuring cylinder and the volume was recorded. The following formula was used to calculate bulk density:

Bulk Density (LBD) = Mass (g)/Volume (ml)

\section{Tapped Density}

The tapped bulk density was measured ${ }^{15}$. $30 \mathrm{~g}$ weight of powder was poured in to a $100 \mathrm{ml}$ measuring cylinder and tapped on a hard surface 30 times from about $2 \mathrm{~cm}$ height and the volume was recorded. Following formula was used to calculate tapped bulk density:

Tapped Density (TBD) = Mass (g)/Volume (ml)

Carr's Index:

Carr's Index (\%) and Hausner's ratio were 
calculated ${ }^{15}$. The values were determined using the following relationship:

C.I. $=(\mathrm{TBD}-\mathrm{LBD} / \mathrm{TBD}) \times 100$

$\mathrm{H} . \mathrm{R}=\mathrm{TBD} / \mathrm{LBD}$

\section{Solubility and Swelling capacity}

Solubility and swelling capacity was measured $^{16} .1 \mathrm{~g}$ of the powder was transferred into a clean dried test tube and weighed $\left(\mathrm{W}_{1}\right)$. The powder was then dispersed in $50 \mathrm{ml}$ of distilled water using stirrer. The slurry so obtained was heated for $30 \mathrm{~min}$ at various temperatures from $60^{\circ} \mathrm{C}$. The mixture after cooling to room temperature was centrifuged for $15 \mathrm{~min}$ at $3000 \mathrm{rpm} .5 \mathrm{ml}$ of the supernatant were dried to a constant weight at $110^{\circ} \mathrm{C}$.

Solubility was calculated as g per $100 \mathrm{~g}$ of powder on dry weight basis. The residue obtained from the above experiment after centrifugation, with the water it retained was quantitatively transferred to the clean dried test tube used earlier and weighed $\left(\mathrm{W}_{2}\right)$. The Swelling capacity was calculated by the following formula: Percentage swelling of starch $=\left[\left(\mathrm{W}_{2}-\mathrm{W}_{1}\right) / \mathrm{W}_{1}\right] \times 100$ Antioxidant Activity

The free radical scavenging activity of the samples was measured in vitro by DPPH assay ${ }^{17} .1 \mathrm{~g}$ of sample is transferred to a clean test tube and $10 \mathrm{ml}$ is ethanol is poured into it. The solution is then kept in water bath at $40^{\circ} \mathrm{C}$ for $3 \mathrm{~h}$ to get the ethanolic extract. Same procedure is repeated to prepare methanolic extract using methanol as solvent. Methanolic and ethanolic DPPH solutions $(0.04 \mathrm{~g} / \mathrm{lit})$ were prepared. Working solution of different concentrations was prepared and the solution was left for $30 \mathrm{mins}$ at room temperature. Absorbance was measured at 517nm. Methanol or ethanol without DPPH was used as blank. Results were expressed as percentage of inhibition of the DPPH radical which was calculated according to the following equation:

$\%$ Inhibition= [(Absorbance Control-Absorbance Sample)/Absorbance Control] x 100

\section{Resistant Starch Estimation}

Resistant starch analysis was done at Chennai Testing Laboratories Pvt. Ltd. Method used was AOAC 19 $19^{\text {th }}$ edition, 2012, 993.19 for soluble fibers and AOAC $19^{\text {th }}$ edition, 2012, 991.42 Microbial Analysis Revival of Probiotics

Freeze-dried Lactobacillus strains were procured from NCIM-CSIR-National Chemical Laboratory, Pune. The cultures were stored at $4{ }^{\circ} \mathrm{C}$ until required. DeMan-Rogosa- Sharpe broth (MRS broth) of pH- 4-5.2 was used to prepare the cell suspensions for probiotic strains ${ }^{18}$. The MRS agar was inoculated with active strains and incubated at $37{ }^{\circ} \mathrm{C}$ for $24 \mathrm{hr}$ under anaerobic condition $^{19}$.

\section{Effect of Prebiotic on the Viability of Probiotic Strain}

The effect of different prebiotics on viability of different probiotic strains was tested ${ }^{19}$. The sterilized prebiotic was added to MRS broth medium by $2 \%$ and inoculated by active probiotic strains and incubated at $37{ }^{\circ} \mathrm{C}$ for $24 \mathrm{~h}$ under anaerobic condition. Also MRS broth inoculated with culture was used as control. The viable count was determined using spread plate method after serial dilutions of the respective broths in physiological solutions and the plates were incubated at $37^{\circ} \mathrm{C}$ for $48 \mathrm{~h}$ under anaerobic condition.

\section{Encapsulation}

Extrusion method was adopted and slightly modified ${ }^{20} .2 .5 \%$ sodium alginate solution and $4 \%$ calcium chloride solution was prepared. Also sodium alginate solution was mixed with prebiotic powder in the ratio 1:1. All the above solutions were sterilsed and allowed to cool. Probiotic culture was mixed and homogenized in sodium alginate solution and sodium alginateprebiotic mixture separately. The solution was loaded in syringe without air bubble and dropped in calcium chloride solution drop wise to form beads. Beads so formed were stored at room temperature.

\section{Encapsulation Efficiency}

$0.5 \mathrm{gm}$ of the beads was disintegrated in $4.5 \mathrm{ml} 0.1 \mathrm{M}$ sodium citrate solution homogenized for 5 minutes and was used to make serial dilutions in physiological solution ${ }^{19}$. The viable count was determined using spread plate method the plates were incubated at $37^{\circ} \mathrm{C}$ for $48 \mathrm{~h}$ under anaerobic condition. All plating was done on triplicates and encapsulation efficiency (EE), which is a combined measurement of efficacy of entrapment and survival of viable cells during microencapsulation procedure, was calculated as follows: $\mathrm{EE}=\mathrm{N} / \mathrm{N}_{0} \times 100$

Where, $\mathrm{N}=$ viable number of entrapped 
cells released from microcapsules and $\mathrm{N}_{0}=$ free cells added to the biopolymer mix during production of microspheres.

\section{Survivability Tests}

The samples were diluted in solutions simulating gastric/gut and homogenized for $5 \mathrm{~min}$ to test tolerance of probiotic strains ${ }^{21}$. To obtain the viable count, $0.1 \mathrm{ml}$ of the dilution of microbes were plated in MRS agar ${ }^{19}$. Plates were incubated at $37^{\circ} \mathrm{C}$ for $24 \mathrm{hr}$ under anaerobic conditions. Samples were checked at at intervals of every two days of storage at room temperature for 1month. Experiments were performed in triplicates.

\section{Statistical Analysis}

Standard deviation was applied for determination of significant difference between means of moisture content, colour readings, cell counts and antioxidant activities ${ }^{22}$.

\section{RESULTSAND DISCUSSION}

\section{Physical Parameters \\ Moisture Content and Water Activity}

Water content or moisture content is the quantity of water contained in a material fruit. During the drying process, moisture loss occurs due to the difference in water vapour pressure between the product and the air surrounding it. The moisture content (wet basis) of the prebiotic powder was found to be $2.05 \pm 0.57 \%$ while the water activity for the prebiotic powder was found in the range of 0.14 to 0.15 (Table 1).

\section{Flow Properties (Density Analysis)}

Bulk density is a measure of heaviness of powder and an important parameter that determines the suitability of powder for the ease of packaging and transportation of particulate foods as well as for infant formulations. Flow properties are decided based on Carr's Index (CI) and Haurrsen's ratio (HR), which is calculated based on Loose Bulk Density (LBD) as well as Tapped Bulk Density (TBD).

A Carr's CI of $<10$ or HR of $<1.11$ is considered 'excellent' flow whereas CI $>38$ or HR $>1.60$ is considered 'very very poor' flow ${ }^{23}$. There are intermediate scales for CI between 11-15 or HR between 1.12-1.18 is considered 'good' flow, CI between $16-20$ or HR between $1.19-1.25$ is considered 'fair' flow, CI between 21-25 or HR between 1.26-1.34 is considered passable flow, CI between $26-31$ or HR between $1.35-1.45$ is considered 'poor' flow, and CI between 32-37 or HR between 1.46-1.59 is considered 'very poor' flow. Based on this discussion and results as shown in Table 1; prebiotic powder had 'good' flow properties. Table 1 show that the solubility of prebiotic powder is significantly high while swelling capacity is average in the range of 400$500 \%$.

\section{Antioxidant Activity}

Scavenging the stable DPPH radical is a widely used method to evaluate the free radical scavenging ability of various samples. The measured DPPH radical scavenging activity and the quality of the antioxidants in the extracts was determined by the percent inhibition values shown is shown in Figure 2.

The F. carica extract scavenging antioxidant activity was significantly increased with increasing concentration of the extract (both ethanolic and methanolic). The percent inhibition values of methanolic extract of $F$. carica were greater than the ethanolic extract of the same. Lack of hydrogen donor bioactive constituents in the extract, slow rate of the reaction between DPPH and the substrate molecules resulting in low readings for antioxidant activity probably might explain the low DPPH antioxidant activity of the $F$. carica extract

\section{Resistant Starch Estimation}

Testing was done at Chennai Testing Laboratories Pvt. Ltd. F. carica can be considered as a good prebiotic source since it has high

Table 1. Physico-chemical parameters for prebiotic powder

\begin{tabular}{lll}
\hline No. & Parameters & Fig Powder \\
\hline 1 & Weight of fruit (g) & 454 \\
2 & Weight of pulp (g) & 329 \\
3 & Weight of powder (g) & 110 \\
4 & Yield (\%) & 24.22 \\
5 & LBD (g/cc) & 0.2535 \\
6 & TBD (g/cc) & 0.2982 \\
7 & HR & 1.1763 \\
8 & CI & 14.99 \\
9 & Moisture Content (wb \%) & $2.05 \pm 0.57$ \\
10 & aW & 0.1430 at $27.4^{\circ} \mathrm{C}$ \\
11 & Solubility & $60 \%$ \\
12 & WHC/SC & $446 \%$ \\
13 & dE & $41.12 \pm 0.005$ \\
\hline
\end{tabular}




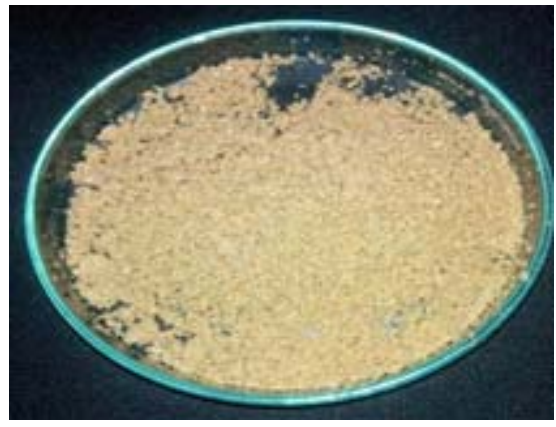

Photo 1. Prebiotic Powder

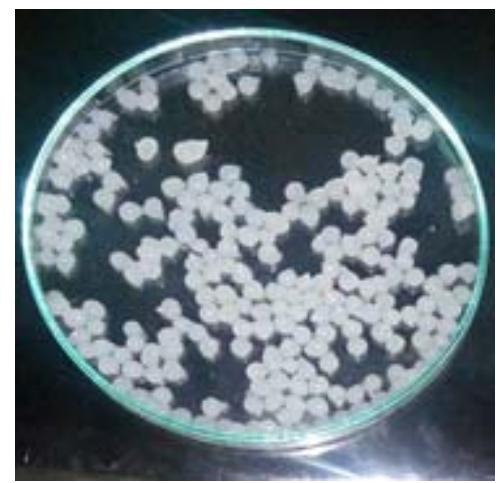

Photo 3. Encapsulated probiotics

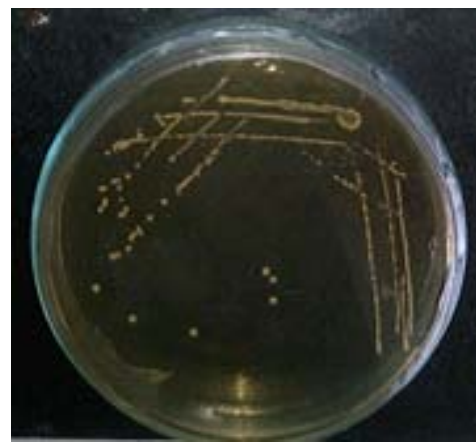

Photo 2. Streak plating for

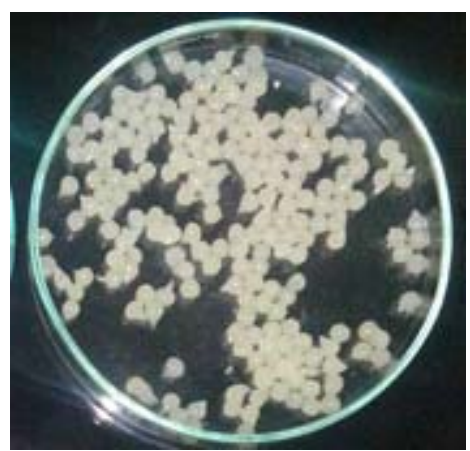

Photo 4. Synbiotically encapsulated probiotics

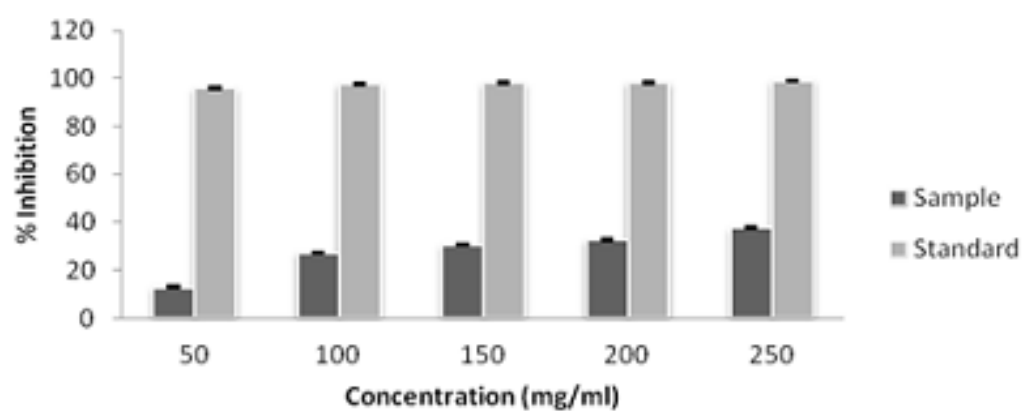

Fig. 1. Percent inhibition of DPPH activity by methanolic extract of prebiotic powder

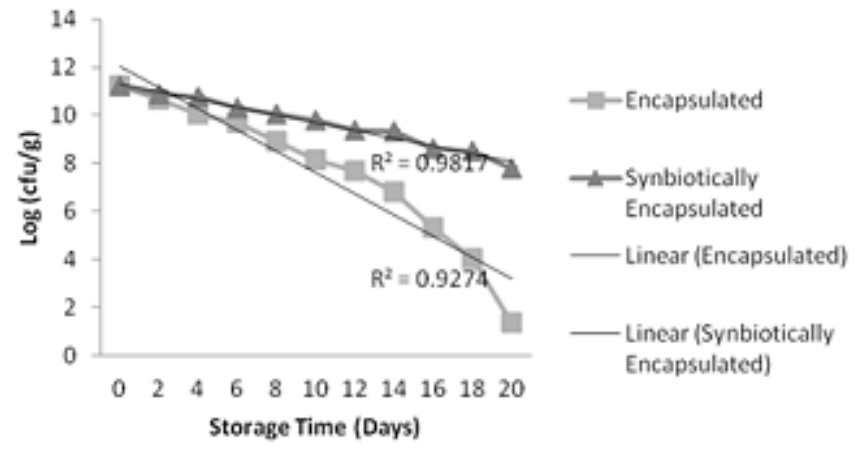

Fig. 2. Survival of probiotics in alginate microcapsules and symbiotic microcapsules in gastric environment at different time intervals 


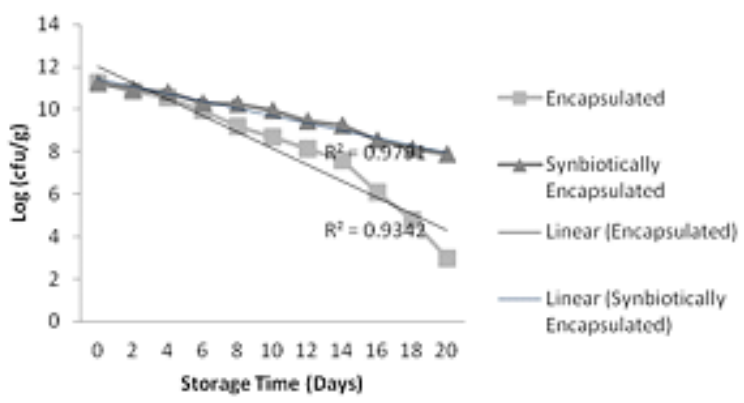

Fig. 3. Survival of probiotics in alginate microcapsules and symbiotic microcapsules in gastric environment at different time intervals

resistant starch content (18.04\%) and less of soluble fibers (2.06\%).

\section{Microbial Analysis}

\section{Revival and Survivability Tests for free cells}

Figure 3 shows successful revival of probiotic strains. These strains were tested for bile and $\mathrm{NaCl}$ tolerance. Probiotics should show good tolerance to low $\mathrm{pH}$ in gastric environment and should exhibit tolerance to bile released in intestinal environment. The lowest $\mathrm{pH}$ recorded has been $\mathrm{pH} 1.5^{24,25}$. A good probiotic should withstand at least $\mathrm{pH} 3.0^{26}$.

Microbial counts in the range of 30-300 $\mathrm{cfu} / \mathrm{ml}$ are considered to be viable in a given specific environment. Free probiotic strains showed a count of $11 \times 10^{7} \mathrm{cfu} / \mathrm{ml}$ in the $\mathrm{NaCl}$ environment whereas a count of as $20 \times 10^{7}$ in the bile environment. As their colony count is not in the required range, it suggests most probiotics were killed by this harsh $\mathrm{pH}$. Also, upon exposure to bile acids, cellular homeostasis disruptions causes the dissociation of lipid bilayer and integral protein of their cell membranes, resulting in leakage of bacterial content and ultimately cell death; thus necessitating encapsulation.

\section{Effect of Prebiotic on Probiotic}

Prebiotic was found to be more effective for viability of the probiotic strains since the viable counts increased from $3.3 \pm 0.05 \times 10^{9} \mathrm{cfu} / \mathrm{ml}$ to5.8 $\pm 0.05 \times 10^{9} \mathrm{cfu} / \mathrm{ml}$. This may be attributed to resistant starch content in the sample.

\section{Encapsulation of Probiotics and Encapsulation Efficiency}

Encapsulated probiotic beads and synbiotically encapsulated beads were formed as shown in figure 4 and 5 respectively. Encapsulation efficiency for them was found to be $99.5 \pm 0.05 \%$.

\section{Survivability of Microencapsulated Probiotics}

Survivability for probiotics was assessed in gastric as well as intestinal environment. Survival of probiotics entrapped in synbiotic microcapsules was significantly improved over those entrapped in alginate microcapsules as shown in Table 2 and 3. Microencapsulation with alginate is able to protect probiotics in food products ${ }^{28}$. Results of the viable counts also showed that viability decreased with increasing storage period for both alginate microcapsules and synbiotic microcapsules (Figure 6, 7).

\section{CONCLUSION}

F. carica (fig) powder was found to have around $18.04 \%$ of resistant starch and $2.06 \%$ of soluble fibers. On the basis of presence of resistant starch in higher amount in F. carica, it was selected as the prebiotic source for the formulation of synbiotic microcapsule. Using the prebiotic source (fig) and Lactobacillus strain as the probiotic, synbiotic formulation was prepared. Sodium alginate was used as carrier material for encapsulation.

The Haurrsen's ratio of 1.1763 and Carr's Index of 14.99 indicated 'good' flow properties. An increase in viability of probiotic strain was observed in the presence of fig powder in the growth medium. Thus based on the results it can be concluded that F. carica can be successfully used as prebiotic for Lactobacillus strain. Also, blending of prebiotics in the coating materials resulted in better protection for the encapsulated organisms and increased cell viability during storage, relative to the prebiotic free variants and microcapsules without prebiotic. 


\section{REFERENCES}

1. Gibson, G. R. and Wang, X. Bifidogenic properties of different types of fructo-oligosaccharides. Food Microbiol. 1994; 11:491-498.

2. Miyazato, S., Nakagawa, C., Kishimoto, Tagami H. and Hara, H. Promotive effects of resistant maltodextrin on apparent absorption of calcium, magnesium, iron and zinc in rats. Eur J Clin Nutr., 2010; 49:165-171.

3. Gibson, G. and Roberfroid, M. Dietary modulation of the human colonic microbiota: introducing the concept of prebiotics. J. Nutr, 1995; 125:1401-1412.

4. Westenbrink, S. K., Brunt, J. W. and Kamp, V.D. Dietary fibre: Challenges in production and use of food composition data. Food Chem. 2012; 140: $562-567$

5. Homayouni, A., Amini, A., Keshtiban, A. K., Mortazavian, A. M., Esazadeh, K. and Pourmoradian, V. Resistant starch in food industry: A changing outlook for consumer and producer. Starch/Stärke., 2013; 65:1-13.

6. Kislev, M. E., Hartmann, A. and Bar-Yosef, O. 2006. Early domesticated fig in the Jordan Valley. Science. 5778 (312):1372-1374.

7. Jeong, M.-R., Kim, H.-Y. and Cha, J.-D. Antimicrobial activity of methanol extract from Ficus carica leaves against oral bacteria. $J$ Bacteriol Virol. 2009; 2(39):97-102.

8. Veberic, R., Colaric, M. and Stampar, F. Phenolic acids and flavonoids of fig fruit (Ficus carica L.) in the northern Mediterranean. Food Chem.2008; 1(106):153-157.

9. Boh, B. 2007. Developments of applications industries des microcapsules. In: Vandamme, Thierry F. (Eds.), Microencapsulation: Des Sciences Aux Technologies. p. 9-22. Lavoisier, Paris

10. Zuidam, N., and VA, N. 2010. Encapsulation Technologies for ActiveFood Ingredients and Food Processing. Springer. USA.

11. L. Serna-Cock, V. Vallejo-Castillo. Probiotic encapsulation. Afr. J. Microbiol. Res., 2013; 7(40):4743-4753

12. Panuwat, D., Anuchita, M., Sirirat, D. Comparison of resistant starch content and survival of Lactobacillus spp. on four different sources of resistant starch. IPCBEE, 2012; 45.

13. Emperatríz P.D., Ronald, M., Elevina, P. and Mily, S. Production and characterization of unripe plantain. Inteciencia. 2008 ; 6(33).

14. Francis, F. J. Colorimetry of foods. Physical Properties of Foods, In M. Peleg and E. B. Bagley (Eds.). p. 105-122. AVI Publishing: Westport, 1983; CT.

15. Arun, R. R. Formulation and evaluation of prednisolone tablets using biodegradable natural polysaccharides as a carrier in colon targeted drug delivery," IJPSR, 2013; 6(4).

16. Olu-Owolabi, B. I., Olayinka, O. O., Adegbemile A. A. and Adebowale, K. O. Comparison of functional properties between native and chemically modified starches from acha (Digitaria Stapf) grains. Food Nutr Sci. 2014; 5: 222-230.

17. Sarker, S. D., Latif, Z. and Gray, A. I. Natural Products Isolation. Humana Press, New Jersey, 2006; NJ, USA.

18. Ashraf, R. and Shah, N. P. Selective and differential enumerations of Lactobacillus delbrueckii subsp. bulgaricus, Streptococcus thermophilus, Lactobacillus acidophilus, Lactobacillus casei and Bifidobacterium spp. in yoghurt - A review. Int j food microbiol. 2011; 149: 194-208.

19. EL-Sayed, H. S., Salama, H. H. and EL-Sayed, S. M. Production of synbiotic ice-cream. Int $J$ ChemTech Res. 2014; 1(7):138-147.

20. L. Farnezah, M. Shahla and M. Maryam. Preparation and characterization of alginate and psyllium beads containing lactobacillus acidophilus. the scientific world j, 2012; 2012.

21. Gbassi, G. K. and Vandamme, T. Probiotic encapsulation technology: From microencapsulation to release into the gut. Pharmaceutics. 2012; 4:149-163.

22. Hernández-Carranza, P., López-Malo, A. and Jiménez-Munguía, M.-T. Microencapsulation quality and efficiency of Lactobacillus casei by spray drying using maltodextrin and vegetable extracts. J Food Res, 2014; 1 (3).

23. Shah, R. B., Mobin, A., Tawakkul and Mansoor, A. March. Comparative evaluation of flow for pharmaceutical powders and granules. AAPS Pharm Sci Tech. 2008; 1(9).

24. Huang, Y. and Adams, M. In vitro assessment of the upper gastrointestinal tolerance of potential probiotic dairy propionibacteria. Int $j$ food microbiol., 2004; 91:253-260.

25. Lin, W.H., Hwang, C.F., Chen , L.W. and Tsen, H.Y. Viable counts, characteristic evaluation for commercial lactic acid bacteria products. Food Microbiol. 2006; 23: 74-81.

26. Fernandez, M., Boris, S. and Barbes, C. Probiotic properties of human lactobacilli strains to be used in the gastrointestinal tract. $J$ appl microbiol. 2003; 94: 449-455.

27. Hansen LT, Allan-Wojtas PM, Jin LA, Paulson AT. Survival of Ca-alginate microencapsulated Bifidobacterium spp. in milk and simulated gastrointestinal conditions. Food Microbiol. 2002. 19:35-45. 